\title{
Evaluation of API Coryne system for identifying coryneform bacteria
}

\author{
A Soto, J Zapardiel, F Soriano
}

\begin{abstract}
Aim-To identify rapidly and accurately coryneform bacteria, using a commercial strip system.

Methods-Ninety eight strains of Corynebacterium species and 62 additional strains belonging to genera Erysipelothrix, Oerskovia, Rhodococcus, Actinomyces, Archanobacterium, Gardnerella and Listeria were studied. Bacteria were identified using conventional biochemical tests and a commercial system (APICoryne, BioMèrieux, France). Fresh rabbit serum was added to fermentation tubes for Gardnerella vaginalis isolates.

Results-One hundred and five out of the $160(65 \cdot 7 \%)$ organisms studied were correctly and completely identified by the API Coryne system. Thirty five (21.8\%) more were correctly identified with additional tests. Seventeen $(10 \cdot 6 \%)$ organisms were not identified by the system and three $(1.9 \%)$ were misidentified.

Conclusions-The system was a good alternative for identification of coryneform organisms. When occasionally performed with some additional tests, this method permits reliable and rapid identification of coryneform organisms compared with conventional methods.
\end{abstract}

(7 Clin Pathol 1994;47:756-759)

Human infections by Coryneform sp are not only increasing but microbiologists are more aware of their possible importance, mainly in high risk and immunosuppressed patients. Over the past two decades other Corynebacterium species, different from Corynebacterium diphtheriae, have been found in severe infections in people. ${ }^{1-3}$ Bacteraemia, endocarditis, peritonitis, osteomyelitis and infection of the urinary and respiratory tracts are the most common infections associated with Corynebacterium sp. ${ }^{4-11}$

These bacteria, which are common in clinical samples, may be disregarded by microbiologists partly because they are considered non-pathogenic or "contaminant," but also because there are no simple methods to identify them correctly in a routine laboratory. ${ }^{2}$ Interest is increasing in the isolation and identification of these organisms, and this led us to evaluate the API Coryne system by comparing it with conventional identification methods. This system is a micromethod for the identification of Gram positive Coryneform organisms that are aerobe or facultatively aerobe, nonspore forming organisms of the following genera: Corynebacterium, Listeria, Actinomyces, Arcanobacterium, Erysipelothrix, Oerskovia, Brevibacterium and Rhodococcus. It also permits the identification of Gardnerella vaginalis which often has a diphtheroid appearance and a variable Gram stain.

We studied 160 organisms in total from different species of the Corynebacterium genus, as well as from other morphological related genera or groups, some of them not included in the API Coryne database.

\section{Methods}

The study was carried out on Gram positive bacilli belonging to the genera Corynebacterium, Erysipelothrix, Oerskovia, Rhodococcus, Actinomyces, Arcanobacterium, Gardnerella and Listeria included in the API Coryne database (table 1). We also studied some organisms belonging to genera that occasionally present a diphtheroid appearance and are not included in the system database (table 2). A total of 160 organisms were evaluated, including 42 reference strains. Clinical isolates were obtained from blood (seven isolates), skin (17 isolates), urine (13 isolates), calcule (one isolate), drainage (one isolate), exudate (one isolate) and abscess (one isolate). The rest of the organisms came from stock collections. All the strains were kept at $-70^{\circ} \mathrm{C}$ before use and cultivated either aerobically or, if necessary, in a $\mathrm{CO}_{2}$ atmosphere for 24 to 48 hours at $35^{\circ} \mathrm{C}$ on heart-infusion agar supplemented with $5 \%$ sheep blood.

The strains were identified using techniques cited by Hollis and Weaver, ${ }^{13}$ Bayston and Higgins, ${ }^{14}$ Coyle $^{1}$ and others. ${ }^{15-17}$ The following tests were used: Gram staining; colony pigmentation; haemolysis; catalase production; urease utilisation, gelatin, hippurate and aesculin hydrolysis; the Voges-Proskauer reaction; nitrate reduction; acid production from glucose, maltose, mannitol, xylose, sucrose, lactose and glycogen in fermentation broth, with the addition of $10 \%$ rabbit serum for Gardnerella vaginalis. Oxidation and fermentation tests were performed for $C$ aquaticum strains. Casein, xanthine, and tyrosine hydrolysis were used to identify Nocardia spp. Most of the strains were identified to species level using these tests but Oerskovia spp were only identified to genus level.

The API Coryne system consists of 20 microtubes containing dehydrated substrates for the demonstration of 11 enzymatic 
Table 1 Corynebacterium species and related genera studied included in the API Coryne database

\begin{tabular}{|c|c|c|c|c|}
\hline Strains & Total & Clinical & Stock & Reference \\
\hline Corynebacterium urealyticum & 27 & 22 & 2 & \multirow{4}{*}{$\begin{array}{l}\text { ATCC } 43042, \\
\text { ATCC } 43043 \text {, ATCC } 43044 \\
\text { ATCC } 43734 \text {, CCUG } 24871 \\
\text { ATCC } 6940 \\
\text { ATCC } 373\end{array}$} \\
\hline Corynebacterium jeikeium & 22 & 15 & 5 & \\
\hline $\begin{array}{l}\text { Corynebacterium striatum } \\
\text { Corynebacterium xerosis }\end{array}$ & 5 & & 4 & \\
\hline $\begin{array}{l}\text { Corynebacternum xerosts } \\
\text { Corynebacterium diphtheriae }\end{array}$ & $\begin{array}{l}3 \\
2\end{array}$ & & $\begin{array}{l}4 \\
2\end{array}$ & \\
\hline $\begin{array}{l}\text { Corynebacterium pseudotuberculosis } \\
\text { Corynebacterium bovis }\end{array}$ & $\begin{array}{l}4 \\
2\end{array}$ & & 3 & \multirow{11}{*}{$\begin{array}{l}\text { ATCC } 19410 \\
\text { ATCC } 7715, \text { CCUG } 2705 \\
\text { ATCC } 10700 \\
\text { ATCC } 15677 \\
\text { ATCC } 19412 \\
\text { ATCC } 29593 \\
\text { ATCC } 29592 \\
\text { ATCC } 23348, \text { CCUG } 541 \\
\text { CCUG } 16556, \text { NCTC } 7907 \\
\text { ATCC } 14665\end{array}$} \\
\hline Corynebacterium pseudodiphtheriticum & 5 & & 4 & \\
\hline Corynebacterium kutscheri & 2 & & 1 & \\
\hline Corynebacterium renale & 2 & & 1 & \\
\hline Corynebacterium cystitidis & 1 & & & \\
\hline Corynebacterium pilosum & 1 & & & \\
\hline Corynebacterium minutissimum & 2 & & & \\
\hline Corynebacterium ulcerans & 6 & & 4 & \\
\hline Corynebacterium aquaticum & 3 & & 2 & \\
\hline Coryneform CDC group $F_{1}$ & 3 & 1 & 2 & \\
\hline Coryneform CDC group $\mathrm{A}_{4}$ & 2 & & 2 & \\
\hline Coryneform $\mathrm{CDC}$ group $\mathrm{G}_{2}$ & 1 & & 1 & \\
\hline Oerskovia sp & 4 & & 3 & \multirow{3}{*}{ ATCC 25835} \\
\hline Erysipelothrix rhusiopathiae & 4 & & 4 & \\
\hline Rhodococcus equi & 8 & 1 & 7 & \\
\hline Listeria monocytogenes & 11 & & 9 & ATCC 19111, NCTC 11994 \\
\hline Listeria innocua & 2 & & 2 & \\
\hline Listeria murrayi & 1 & & & \multirow{4}{*}{$\begin{array}{l}\text { ATCC } 25401 \\
\text { ATCC } 25400\end{array}$} \\
\hline Listeria grayi & 1 & & & \\
\hline Listeria ivannovii & $i$ & & 1 & \\
\hline Listeria seeligeri & 2 & & 2 & \\
\hline Arcanobacterium haemolyticum & 5 & & 4 & ATCC 9345 \\
\hline Actinomyces pyogenes & 4 & & 3 & ATCC 19411 \\
\hline Gardnerella vaginalis & 4 & 1 & 2 & ATCC 14018 \\
\hline
\end{tabular}

Table 2 Other species studied not included in the API Coryne database

\begin{tabular}{lllll}
\hline Strains & Total & Clinical & Stock & Reference \\
\hline Corynebacterium ammoniogenes & 1 & & & ATCC 6871 \\
Corynebacterium callunae & 1 & & & ATCC 15991 \\
Corynebacterium flavescens & 1 & & & ATCC 10340 \\
Corynebacterium vitarumen & 1 & & ATCC 10234 \\
Clavibacter michiganense & 1 & & CCUG 580 \\
Curtobacterium flaccumfaciens & 1 & & & CCUG 23824 \\
Rhodococcus rhodochrous & 1 & & & ATCC 11048 \\
Propionibacterium avidum & 2 & 1 & & ATCC 25577 \\
Propionibacterium granulosum & 1 & & 1 & ATCC 25564 \\
Rothia dentocariosa & 2 & & ATCC 17931 \\
Nocardia asteroides & 2 & & ATCC 19247 \\
Nocardia brasiliensis & 1 & & & ATCC 19296 \\
Nocardia farcinica & 1 & & ATCC 3318 \\
Lactobacillus acidophilus & 2 & & 1 & ATCC 832 \\
\hline
\end{tabular}

activities (nitrate reduction, pyrazinamidase, pyrrolidonyl arylamidase, alkaline phosphatase, $\beta$ glucuronidase, $\beta$ galactosidase, $\alpha$ glucosidase, $\mathrm{N}$-Acetyl- $\beta$ glucosaminidase, aesculin, urease and hydrolysis of gelatin) or the fermentation of eight sugars (glucose, ribose, xylose, mannitol, maltose, lactose, sucrose and glycogen). The catalase test was performed by adding 1 drop of hydrogen peroxide $(3 \%)$ to the aesculin or gelatin test. After one minute the appearance of bubbles corresponded to a positive reaction.

The inoculum was prepared in distilled water with a turbidity greater than 6 on the McFarland scale measured by comparing it with the turbidity control included in the kit. This inoculum was used for enzymatic tests. To carry out the fermentation tests, about 0.5 $\mathrm{ml}$ of bacterial suspension was transferred to an ampoule containing $2 \mathrm{ml}$ of GP medium, with the addition of $10 \%$ rabbit serum for Gardnerella vaginalis. After homogenisation, this new suspension was distributed into the fermentation tubes and overlayed the cupules with mineral oil. The same was done for the urea hydrolysis tube. The strip was then incubated at $37^{\circ} \mathrm{C}$ for 24 hours. Blood agar was also incubated as a control.
The readings, except for the aesculin, urease, and gelatin tests, were done after adding the appropriate reagents. The fermentation reactions were considered positive when they turned yellow. Identification was made using the table provided by BioMèrieux and, when there were difficulties, by contacting the API computer service. The interpretation was carried out adding data on macroscopic and microscopic morphology, catalase, and haemolysis, as well as the numerical profile of the API Coryne system.

All the strains with a profile of "acceptable" identification or better were considered correctly identified. Some additional tests were performed on those strains with a profile of "good identification to genus" within the group $C$ renale/C cystitidis and $C$ aquaticum/ Coryneform CDC group A, according to the manufacturer's protocol. These tests included growth in $6 \%$ sodium chloride, production of acid from trehalose or fructose, the VogesProskauer reaction, the CAMP test, growth at a $\mathrm{pH}$ of 5.4 and Tween- 80 hydrolysis. The strains with a profile of "low", "doubtful" or "insufficient discrimination" were considered unidentified. When the profile was good at species level but did not match the conventional identification, it was considered incorrectly identified.

\section{Results}

Of the 160 organisms studied using the API system, $105(65 \cdot 7 \%)$ of them were correctly and completely identified in 24 hours to species level, 35 more $(21 \cdot 8 \%)$ were incompletely identified but finally correctly identified with additional tests, $17(10.6 \%)$ were not identified as the profile number did not correspond to any organism, and in three $(1.9 \%)$ cases the strains were misidentified. Most strains (87.5\%) were correctly identified in 24 hours or after additional tests (table 3 ).

Six strains of $C$ jeikeium had a good profile at genus level (profile number 2100324) and may represent a less common biotype. Additional tests were required for correct identification (growth in $6 \%$ sodium chloride and the production of acid from fructose). One strain of $C$ striatum required the VogesProskauer test as an additional test to differentiate it from Coryneform CDC group $\mathrm{G}_{2}$. None of the $C$ aquaticum strains was correctly and completely identified by the API system. One of them required growth at $42^{\circ} \mathrm{C}$ and oxidation or fermentation tests as additional tests. The other two were misidentified as $R$ equi and Listeria spp. The strains belonging to the group $C$ renale/ $C$ cystitidis are indistinguishable using the API system, as they have the same profile. Additional tests such as growth in $\mathrm{pH} 4.5$ and Tween- 80 hydrolysis were required to differentiate both of them. All the Coryneform CDC groups were correctly identified in 24 hours.

The species of "related genera" included in this study were correctly identified. $L$ monocytogenes and $L$ innocua required the CAMP test and haemolysis to distinguish between them, 
Table 3 Distribution of API Coryne identification

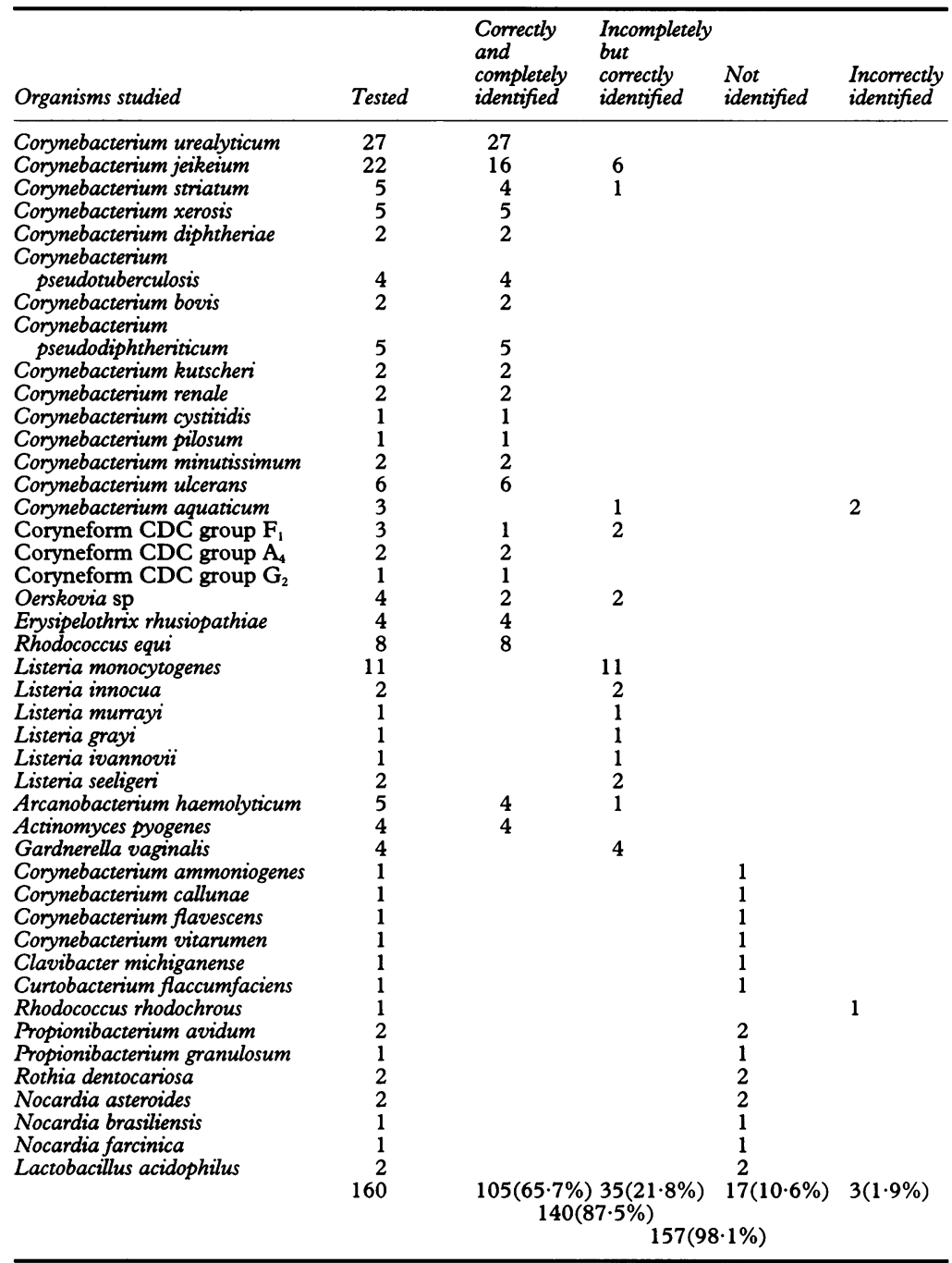

as the manufacturer recommends. All the $G$ vaginalis strains required $10 \%$ rabbit serum to be added to the inoculum, to be properly identified. Oerskovia sp required the API database.

We also included four non-pathogenic species of corynebacteria and 14 strains belonging to seven genera of aerobic, aerotolerant, or branched bacteria that can present a diphtheroid appearance and are not included in the API Coryne system database. Seventeen of these strains corresponded to profiles of "low", "doubtful" or "insufficient discrimination" or non-existent profiles and were regarded as not having been identified by the system. Rhodococcus rhodochrous was misidentified as $R$ equi (profile number 2151004).

\section{Discussion}

Over the past decades an increase in opportunistic infections by Gram positive diphtheroids has aroused interest in their identification in clinical laboratories. Conventional methods are slow and complex because of the number of tests that have to be performed which in the end can only identify between $40 \%-60 \%$ of the isolates. ${ }^{1}$
Previous investigations have done similar studies testing commercial systems for the study and identification of coryneforms. ${ }^{18-20}$ The API Coryne is a commercial system for the identification of aerobe or facultative, non-branched and non-spore forming Gram positive diphtheroid rods. In the clinical laboratory the isolation of organisms that have these characteristics but are not truly coryneforms is common and could be tested with the API Coryne system by mistake. This is why we included in this study 146 strains of Corynebacterium species and related genera as well as 14 strains of seven genera that occasionally could be mistaken for a diphtheroid.

The API Coryne system was able to identify correctly and completely $105(65 \cdot 7 \%)$ out of the total of the organisms studied. Thirty five $(21 \cdot 8 \%)$ more strains were correctly identified with the aid of the additional tests or the API computer database. Accordingly, the API Coryne system identified 140 out of the 160 $(87 \cdot 5 \%)$ strains studied.

The number of unidentified micro-organisms was 17 out of $160(10.6 \%)$. Unidentified organisms belonged to species not contained in the database, such as non-pathogenic or plant pathogenic species of Corynebacterium or related genera and unrelated organisms that occasionally present a diphtheroid morphology. An $R$ rhodochrous strain was misidentified as $R$ equi. Only three (1.9\%) strains out of the 160 studied were misidentified with the API Coryne system.

Our study shows that the API Coryne system produced a similar or slightly lower percentage of correctly identified organisms compared with other investigations, ${ }^{21-24}$ but it has to be remembered that many species we studied are not included in the API Coryne database. In general, most Corynebacterium species and related genera were correctly identified to species level with or without additional tests, as reported before. ${ }^{21}{ }^{22}$ Several species required additional tests especially in those genera other than Corynebacterium, such as all the Listeria species. ${ }^{21}$

The main difference of our work is the higher number of species that are not included in the API Coryne database and were tested to challenge the system. Only one out of the 18 strains of species not included in the API Coryne database was incorrectly identified. The rest were not identified with the system, but if we had checked whether they were anaerobic or aerobic, the Gram morphology, and for acid fast bodies, they probably would have been.

It is very important to follow the manufacturer's recommendations in respect of the preparation and amount of inoculum needed. A low inoculum gives no definitive results in bacteria with a slow or difficult growth. This happened to us with $G$ vaginalis for which we had to add $10 \%$ rabbit serum to the GP medium.

We recommend that respiration, microscopic morphology (coryneform), spores; macroscopic appearances-colony size, pigmentation, and haemolysis should all be 
checked for optimal use of the API Coryne system.

The fact that it was possible to identify 140 $(87.5 \%)$ or $157(98 \cdot 1 \%)$ out of the 160 studied micro-organisms with the API Coryne system, depending on the inclusion of the unidentified organisms, shows that the API Coryne system is very reliable and accurate. Most of the Gram positive bacilli isolated from clinical samples were identified in under 48 hours, compared with at least one week by standard methods, an important factor to bear in mind.

This work was supported by a Fundación Conchita Rábago grant from Fundación Jiménez Díaz and Fondo de Investigación Sanitaria (FISS) from the Spanish Ministry of Health.

1 Coyle M, Lipsky BA. Coryneform bacteria in infectious diseases: clinical and laboratory aspects. Clin Microbiol Rev 1990;3:227-46.

2 Marshall RJ, Johnson E. Corynebacteria: incidence among samples submitted to a clinical laboratory for culture. Med Lab Sci 1990;47:36-41.

3 Young V, Meyers W, Moody M, Schimpf S. The emergence of coryneform bacteria as a cause of nosocomial infections in compromised hosts. Am $\mathcal{F}$ Med 1981;70: 646-50.

4 Ena J, Berenguer J, Pelaez T, Bouza E. Endocarditis caused by Corynebacterium group D2. F Infect 1991;22: 95-6.

5 Jackman P, Pitcher DG, Pelczynska S, Borman P. Classification of corynebacteria associated with endocarditis (Group $\mathrm{JK}$ ) as a Corynebacterium jeikeium sp.nov. System Appl Microbiol 1987;9:83-90.

6 Jacobs NF, Perlino CA. "Diphtheroid" pneumonia. South 7 Med 1979;72:475-6.

7 Langs JC, de Briel D, Sauvage C, Blickle JF, Akel H. Endocardite a Corynebacterium du groupe D2, à point de départ urinaire. Med Mal Infect 1977;5:293-5.

8 Marshall RJ, Routh K, MacGowan AP. Corynebacterium CDC group D2 bacteraemia. F Clin Pathol 1987;40: 813-4.
9 Maskell $\mathrm{R}$, Pead L. Corynebacteria as urinary pathogens. f Infect Dis, 1990;162:781-2.

10 Nadal D, Schwobel A, von Graevenitz A. Corynebacterium group D2 and urolithiasis in a boy with megacalycosis. f Infect 1988;16:245-7.

11 Soriano F, Aquado JM, Ponte C, Fernandez-Roblas R Rodriguez-Tudela JL. Urinary tract infection caused by Corynebacterium group D2. Report of 82 cases and Corynebacterium group D2. Report of 82 cases and
review of the literature. Rev Infect Dis 1990;12:1019-34.

12 Clarridge J. When, why, and how far should coryneforms be identified? Clin Microbiol Newslet 1986;8:32-4.

13 Hollis DG, Weaver RE. Gram-positive organisms: a guide to identification. Centers for Disease Control: Atlanta, Georgia, 1985

14 Bayston R, Higgins J. Biochemical and cultural characteristics of "JK" coryneforms. 7 Clin Pathol 1986;39:654-60.

15 Finegold SM, Baron EJ. Diagnostic microbiology. Princeton: The CV Mosby Company 1986.

16 Keddie RM, Bousfield IJ. Cell wall composition for the classification and identification of coryneform bacteria. In: Goodfellow M, ed. Microbiological classification and In: Goodfellow M, ed. Microbiological classification and

17 Krech T, Hollis DG. Coryne bacterium and related organisms. In: Manual of clinical microbiology. Washington, DC: American Society for Microbiology, 1991:277-86.

18 Grasmick AE, Bruckner DA. Comparison of rapid identification method and conventional substrates for identification of Corynebacterium group $\mathrm{JK}$ isolates. $f \mathrm{Clin}$ Microbiol 1987;25:1111-2.

19 Kellie MC, Smith ID, Anstey RJ, Thornley JH, Rennie RP. Rapid identification of antibiotic-resistant corynebacteria with the API 20 S system. I Clin Microbiol 1984;19:245-7.

20 Tillotson G, Arora M, Robbins M, Holton J. Identification of Corynebacterium jeikeium and Corynebacterium CDC group D2 with the API 20 Strep system. Eur $\mathcal{F}$ Clin Microbiol Infect Dis 1988;7:675-8.

21 Freney J, Duperron MT, Courtier C, Hansen W, Allard F, Boeufgras JM, et al. Evaluation of API Coryne in comparison with conventional methods for identifying coryneform bacteria. 7 Clin Microbiol 1991;29:38-41.

22 Gavin SE, Leonard RB, Briselden AM, Coyle MB. Evaluation of the Rapid CORYNE identification system for Corynebacterium species and other coryneforms. for Clin Microbiol 1992;30:1692-5.

23 Peloux P, Caniaux I. Identification des corynebacteries et germes apparentes. Apport d'une nouvelle galerie d'identification: API CORYNE. Feuillets de Biologie 1990;23:27-34.

24 Morrison JRA, Tillotson GS. Identification of Actinomyces (Corynebacterium) pyogenes with the API 20 Strep system. $\mathcal{f}$ Clin Microbiol 1988;26:1865-6. 